\title{
Effects of intraruminal infusions of sodium salts on selection of hay and concentrate foods by sheep
}

\begin{abstract}
Infusion of salts of short-chain fatty acids into the rumen of sheep depresses food intake but the relative importance of the effect of the acids and of osmolality are not fully understood. Three experiments were carried out in which sodium acetate $(\mathrm{NaAc})$ and sodium chloride $(\mathrm{NaCl})$ were infused for $3 \mathrm{~h}$ at $4 \mathrm{~m} / \mathrm{min}$ and compared with water controls. The effects on the intakes of a concentrate food and hay were examined to study the effect of osmotic and acid manipulation of the rumen on dietary choice. In the first experiment the foods were continuously available while in the second and third the foods were given for $3 \mathrm{~min}$ at $1.5-\mathrm{h}$ intervals. Salt infusions depressed concentrate intake without significant effect on the intake of hay. The effect of $\mathrm{NaAc}$ tended to be greater than that of $\mathrm{NaCl}$ and persisted after the end of infusion. The weight of concentrate eaten during the 3-min tests was significantly and negatively related to both acetate and sodium concentrations in rumen fluid. The weight of hay eaten was negatively related to concentrate intake. The results demonstrate that the treatments imposed had a differential effect on intake, only depressing that of the concentrate food. They also suggest that, as $\mathrm{NaAc}$ has a greater effect than $\mathrm{NaCl}$, the influence on feeding is due both to the osmotic load and the acid effect.
\end{abstract}

